\title{
A experiência vivida junto ao livro Habitar em risco
}

\author{
Ricardo Ojima*
}

MARANDOLA JR., E. Habitar em risco: mobilidade e vulnerabilidade na experiência metropolitana. São Paulo: Blucher, 2014. 248p.

O livro publicado por Eduardo Marandola Jr. em 2014 é resultado da revisão de sua tese de doutorado em geografia pela Universidade Estadual de Campinas (Unicamp), defendida em 2008 e orientada pelo prof. Daniel Hogan. Trata-se do segundo livro da Coleção População e Sustentabilidade, da Editora Blucher, e que homenageia a trajetória acadêmica de Hogan nos estudos sobre População e Ambiente. Mas não seria justo se eu não me permitisse lançar mão da minha experiência ao longo dos anos em que convivi com as discussões e debates destes dois parceiros intelectuais. De certa forma, tento de maneira muito rudimentar aplicar aqui a metodologia utilizada pelo autor e que é descrita a partir da página 201 do livro. Enfim, esse texto é escrito na perspectiva de uma experiência que “envolve percepção, cognição, sensação representação e imaginação" (MARANDOLA JR., 2014, p. 201).

Foi ao longo dos anos de orientação da tese de Marandola Jr. que o debate sobre riscos e vulnerabilidades socioambientais proporcionou um conjunto de artigos, livros e capítulos sobre um tema que ainda não estava totalmente consolidado na literatura brasileira. Conceitos de origens diversas e abordagens múltiplas só poderiam ser enfrentados numa

\footnotetext{
*Universidade Federal do Rio Grande do Norte (UFRN), Natal-RN, Brasil (ricardo.ojima@gmail.com).
} 
perspectiva interdisciplinar. Esse era o desafio posto por Daniel Hogan e que o autor do livro aceitou com sua tranquilidade e bom humor típicos. Foram inúmeros textos, debates, congressos, seminários e reuniões ao longo de quatro ou cinco anos de intensa efervescência intelectual da qual os colegas podiam compartilhar e aprender. Havia ali uma cumplicidade intelectual pouco comum nos meios acadêmicos e que muitas vezes causava uma ponta de inveja aos demais envolvidos naquele processo. Mas, ao final, existia ali uma parceria cordial e leve que transbordava inspiração para todo o grupo. E mais do que isso: esse grupo de pesquisa tornou-se o casulo protetor quando a referência já não mais estava presente.

Discutir a vida na metrópole não seria nada novo. Muitos pesquisadores desde Simmel (1902) já tinham percebido elementos distintivos nesse tipo de formação urbana moderna. O que o livro Habitar em risco traz de novo é uma abordagem para ajudar a compreender algumas das interfaces que permeiam as (in)certezas vividas na metrópole. Para tanto, o autor empreende uma perspectiva da experiência vivida de base fenomenológica, cuja análise não se limita ao local de moradia, abrangendo o complexo tecido estendido do habitar urbano no contexto da mobilidade metropolitana. A casa, que antes era um refúgio e símbolo de segurança, passa a ser apenas mais um dos contextos nos quais vivemos com medo. Viver na metrópole, portanto, é conviver com diversas vulnerabilidades simultâneas e sobrepostas.

A mobilidade urbana é hoje uma das grandes preocupações sociais e políticas. Portanto, sua compreensão não poderia se limitar ao físico, ao material, ao perceptível aos olhos. Mover-se dentro da metrópole é parte daquilo que constitui a própria metrópole. Ampliamos nossa mobilidade à força, como necessidade das estratégias de reprodução e produção social, e as nossas experiências vão além da casa e do trabalho. Multiplicamos o risco, recriamos nossas vulnerabilidades.

Para explorar essa trama de relações, o autor divide o livro em três partes. Na primeira, "Geografia do riscos", são abordados com rigor os conceitos que, numa perspectiva interdisciplinar, precisariam ser discutidos. Resgatando o campo geográfico, Marandola Jr. mostra como o objeto analítico dos riscos e vulnerabilidades metropolitanos pode ser apreendido a partir de diversas áreas do conhecimento. Fica clara a influência de seu orientador na trajetória intelectual empreendida ao longo dos textos publicados em conjunto e se engana aquele que se deixa levar pelo título da seção, pois a geografia dos riscos serve aos interesses dos estudos do urbano/metropolitano e de suas vulnerabilidades e não é um tratado sobre geografia propriamente dito.

Trata-se de uma leitura atenta sobre os temas que cercam o debate sobre riscos, desde a sua gênese até a sua interpretação social. Para tanto, o autor lança mão de um conjunto de autores relevantes para a área de estudos que, com certeza, sintetizam parte expressiva dessa literatura de maneira convergente. Embora não seja o objeto do trabalho, mesmo o leitor que se interesse pela busca de indicadores de risco/vulnerabilidade e afins terá elementos para uma boa fundamentação conceitual de formas de mensuração de tais ideias. 
Enfim, o autor avança sobre uma abordagem fenomenológica muito pouco explorada pela literatura brasileira e nos permite enxergar o mundo com o olhar diferenciado e, por isso, avança numa fronteira de conhecimento. Em um olhar-se de dentro para fora para pensar o que podemos entender dos riscos contemporâneos.

A segunda parte do livro, "Mobilidade e permanências", aborda a necessidade de entender a metrópole a partir da região enquanto espaço vivido. Assim, a mobilidade passa para o centro do debate para configurar o contexto metropolitano, lançando mão do conceito de espaço de vida para integrar não apenas uma abordagem micro-macro, mas sobretudo quali-quanti para pensar o modo de vida metropolitano. A metrópole deve ser entendida, então, enquanto este complexo sistema de relações materiais e simbólicas que circundam o indivíduo ao longo de seus ciclos de vida, os quais favorecem o complemento e ampliação da experiência de vida na metrópole. A mobilidade aqui transgride o aspecto demográfico e parte para uma leitura da experiência vivida. Mas será que a demografia só se faz com aquilo que se pode mensurar numericamente? Não é nem de longe uma pergunta que o autor se debruça nesta obra, mas com certeza é uma resposta que um demógrafo que acompanha essa leitura buscará. Ou será que o imensurável não afeta a dinâmica populacional?

Sem escapar demais do tema do livro, fica clara a necessidade de se repensar o conceito de mobilidade sob uma leitura demográfica. Com certeza a mobilidade é um fenômeno de interesse demográfico, pois pode interferir diretamente nos componentes demográficos. Enfim, ao relacionar os espaços de mobilidade por meio dos ciclos de vida (que um demógrafo poderia aproximar por grupos de idade), já temos uma análise que pode ser apropriada nos estudos de população.

Assim, o lugar da segurança, onde se vive em um sistema de proteção, é fragmentado pela ampliação do contexto complexo e fragmentado da metrópole. E a mobilidade coloca as pessoas fora do eixo, fora do casulo. Assim, ao mesmo tempo que proporcionam uma ampliação de oportunidades de diversas perspectivas, as metamorfoses do espaço de vida ao longo do tempo também consolidam o contexto das incertezas e inseguranças. Portanto, entender o risco passaria pelo entendimento das formas de viver a cidade/metrópole. $E$ isso ocorre de maneira distinta de acordo com ciclos de vida e seus contextos.

Por fim, a terceira parte do livro, "Habitar a metrópole”, coloca em evidência a aplicação dessas leituras conceituais. Por meio de uma abordagem com foco nas biografias, o fechamento do livro mostra a importância e a interlocução dos esforços teóricos construídos nas partes anteriores. A partir disso, o autor ilustra a abordagem que pretendeu enfatizar desde o início, mostrando com clareza a integração com as leituras teóricas na trajetória dos indivíduos que foram objeto do estudo. Assim, fica claro que é fundamental entender as experiências vividas pelo ser metropolitano para a compreensão dos fenômenos sociais e ambientais que cercam a vulnerabilidade, os riscos e as inseguranças metropolitanas.

Ao fim, o autor reconhece a necessidade de integração com metodologias combinadas de origem quantitativa. De fato, nenhum indicador deve ser confundido com o próprio 
fenômeno que se pretende mensurar, portanto, não há metodologia de análise que seja mais verdadeira do que outra. Aqui fica a contribuição de um olhar novo para um problema que a visão tradicional parecia estar estagnada. E Daniel, ao perceber essa potencialidade, não apenas apoiou de forma sistemática ao longo destes anos, mas também, de modo perspicaz, colocou-a em confronto com outras áreas de conhecimento que tradicionalmente não traziam essa abordagem.

Foi nessa trajetória que aprendi, ainda amadoristicamente, como a interdisciplinaridade é muito mais do que juntar na mesma mesa pessoas de áreas de conhecimento distintas. São necessários esforço e, principalmente, boa vontade para sair da sua zona de conforto (ou da segurança que cria certezas, na perspectiva da obra) para reconhecer sua limitação em muitos conhecimentos. Na verdade, assim como o viver na metrópole, sair do seu casulo protetor é sentir-se inseguro e vulnerável. Portanto, o mais fácil é ignorar nossa limitação e recusar a necessidade de ampliar nossa experiência. Não é simples ser diferente disso, pois, nessa trajetória e na ampliação dos nossos espaços de vida, nos deparamos com desafios cada vez maiores e externalidades mais contundentes. Lidar com abordagens diferentes das nossas certezas é um esforço de humildade e, portanto, arriscaria dizer que a busca da interdisciplinaridade na ação individual do pesquisador é, principalmente, ser humilde.

Enfim, a publicação desse livro (assim como a Coleção) em homenagem ao prof. Daniel Hogan não é apenas uma referência à sua trajetória intelectual e ao seu legado. Na minha experiência, essa publicação é também uma homenagem ao significado das conversas e incentivos que ficaram como um legado intrínseco nas nossas trajetórias. A área de População, Espaço e Ambiente, no âmbito da Abep, sempre permitiu essa incorporação das divergências teóricas e isso se tornou responsável pelo amadurecimento rápido de uma área que não é nem de longe uma alusão ao ambientalismo radical, mas sim uma abordagem crítica das relações complexas da dinâmica demográfica.

Desafiar o conhecimento consolidado e estar atento às revoluções científicas eram características de Hogan que sempre nos inspiraram. Esse conjunto de publicações da Coleção População e Sustentabilidade tenta demonstrar isso. Escrever esse texto é, portanto, também um convite a essa reflexão. A experiência que tive não pode ser transferida, mas talvez possa ser inspiração para que se construa um espaço de vida desafiador reconhecendo humildemente nossas limitações para aprender com o estranhamento. Foi um prazer reler este trabalho concluído em forma de livro não apenas pelo fato de confirmar a capacidade de síntese e esclarecimento do autor, mas também por poder tornar público, aqui, parte das experiências que me fizeram chegar até aqui.

\section{Sobre o autor}

Ricardo Ojima é sociólogo e doutor em demografia pela Universidade Estadual de Campinas - Unicamp. Professor do Departamento de Demografia e Ciências Atuariais - DDCA, da Universidade Federal do Rio Grande do Norte - UFRN. 


\section{Endereço para correspondência}

Universidade Federal do Rio Grande do Norte - UFRN

Centro de Ciências Exatas e da Terra - CCET, Departamento de Demografia e Ciências

Atuariais - DDCA

Avenida Salgado Filho, s/n, Lagoa Nova

59078-900 - Natal-RN, Brasil

Recebido para publicação em 06/09/2015

Recomendado para publicação em 29/10/2015

Aceito para publicação em 18/11/2015 